\title{
Effect of Lavender Hydro Alcoholic Extract on Liver's Enzymes and Histology in Small Laboratory Mice
}

\author{
Modaresi M.* PhD, Arefian S. ${ }^{1} M S c$ \\ *Physiology Department, Agriculture Faculty, Isfahan (Khorasgan) Branch, \\ Islamic Azad University, Isfahan, Iran \\ ${ }^{1}$ Biology Department, Science Faculty, Taft Branch, Payam-e-Noor University, Taft, Iran
}

\begin{abstract}
Aims: In traditional medicine, lavender is known as one of the effective herbal drugs on liver function, but so far, side effects of the lavender flower extract on liver biochemistry have not been studied. The aim of this study was to find the effect of lavender hydro-alcoholic extract on liver's tissue and enzymes.

Materials \& Methods: In this experimental study, 50 mature female small mice were divided into 5 groups (each 10); control, placebo and 3 experimental groups. Placebo group received normal saline and treatment groups received the hydro-alcoholic extract of lavender in $50,100,200 \mathrm{mg} / \mathrm{kg}$ doses 10 times every other day, interperitoneally. The levels of liver enzymes (ALT, AST and ALP) were measured and liver tissue was studied after 20 days. Data were analyzed using SPSS 16 software and variance test.

Findings: ALT enzyme was increased significantly in $200 \mathrm{mg} / \mathrm{kg}$ group comparing with the control group $(\mathrm{p}<0.05)$. The level of AST enzyme was decreased significantly in $100-$ and $200 \mathrm{mg} / \mathrm{kg}$ groups and the ALP amount was decreased significantly in $200 \mathrm{mg} / \mathrm{kg}$ group in proportion to control group $(\mathrm{p}<0.05)$. In histological studies, liver tissue of $50-$ and $100 \mathrm{mg} / \mathrm{kg}$ did not show significant pathological changes but obvious pathological changes (necrotic tissue) was observed in liver tissue of $200 \mathrm{mg} / \mathrm{kg}$ group.

Conclusion: The hydro-alcoholic lavender extract causes reduction of AST and ALP enzymes in 100 - and $200 \mathrm{mg} / \mathrm{kg}$ doses, but the $200 \mathrm{mg} / \mathrm{kg}$ dose results in severe liver tissue necrosis.
\end{abstract}

\section{Keywords}

Lavandula [http://www.ncbi.nlm.nih.gov/mesh/68027523];

Liver [http://www.ncbi.nlm.nih.gov/mesh/68008099];

Mice [http://www.ncbi.nlm.nih.gov/mesh/68051379]

\footnotetext{
${ }^{*}$ Corresponding Author

Tel: +983135354001

Fax: +983135354060

Address: Physiology Department, Agriculture Faculty, Islamic Azad University, Isfahan (Khorasgan) Branch, Arghavanieh, Jey Street, Isfahan, Iran

mehrdad_modaresi@hotmail.com

Received: January 17, $2015 \quad$ Accepted: November 30, 2015 ePublished: December 15, 2015
} 
مقدمه

امروزه اكثر داروهاى كياهى بدون انجام آزمايشات استاندارد وارد بازار مىشوند و تصور عموم بر اين است كه اين داروها فاقد سمّيت

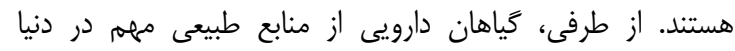

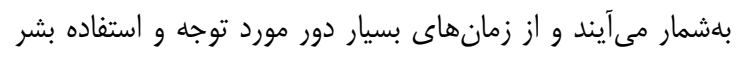

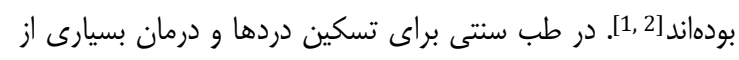

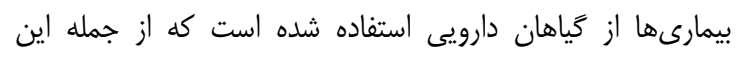

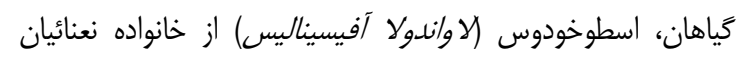

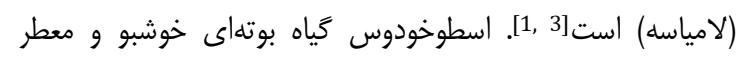

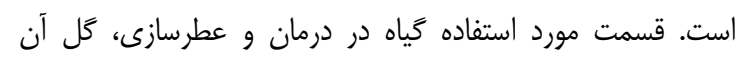

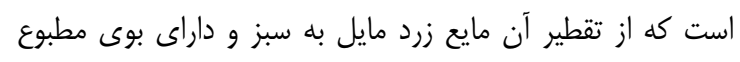

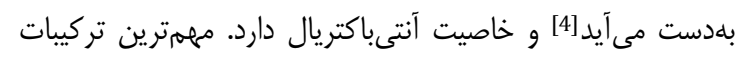

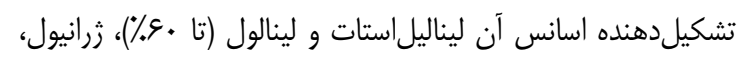
كومارين، فلاونوئيد، بورنئول، استرول، هيدروكربنهاى ترينين ترينوئيد،

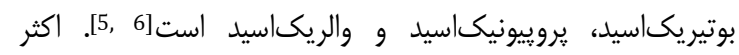

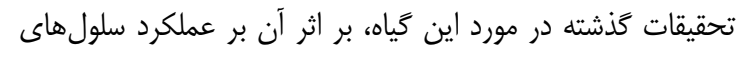

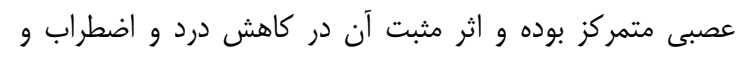

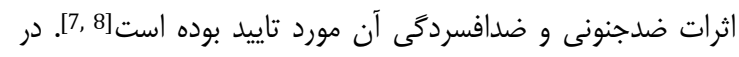
طب سنتى، اسطوخودوس بهعنوان يكى از داروهاى موثر بر عملكرد

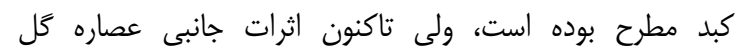

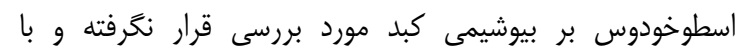

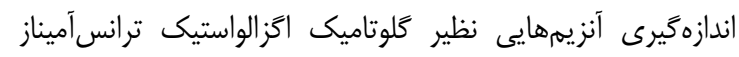

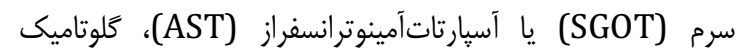
ييروويك ترانسآميناز سرم (SGPT) يا آلانينآمينوترانسفراز و آلكالينفسفاتاز (ALP) مى (ALP) يَى برد[9]. با توجه به مطالب فوق، هدف يروهش حاضر، تعيين تاثير عصاره

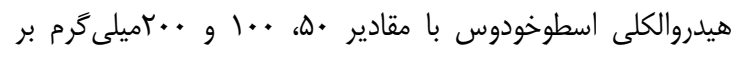

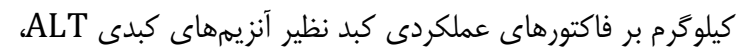

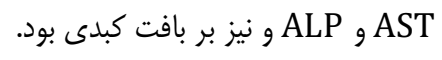

\section{مواد و روشها}

در اين مطالعه تجربى كه در سال سوسا در دانشگاه ييام نور انجام

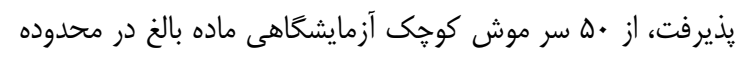

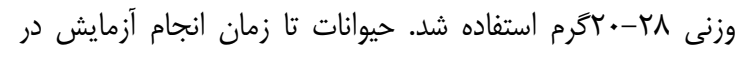

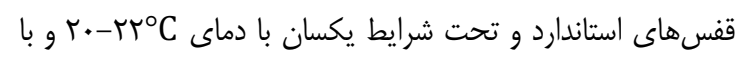
جرخه نورى طبيعى نخمهدارى شدند و آب و غذا بهميزان كافى در

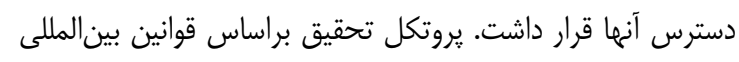

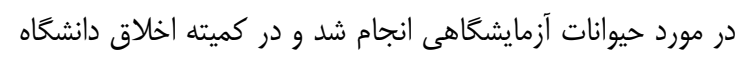
ييام نور اصفهان به تصويب رسيد.

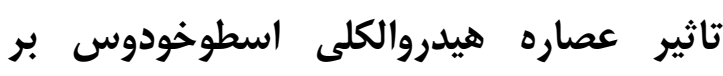

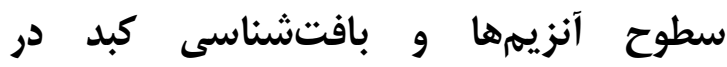
موش سهاى كوجى آزمايشكاهى

PhD مهرداد مدرسى

كروه فيزيولوزى، دانشكده كشاورزى، واحد اصفهان (خوراسكان)، دانشعاه آزاد اسلامى، اصفهان، ايران

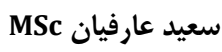

كروه زيستشناسى، دانشكده علوم، مركز تفت، دانشكاه بيام نور، تفت، ايران

קצكيده

اهداف: در طب سنتى، اسطوخودوس بلهنوان يكى از داروهاى گياهى

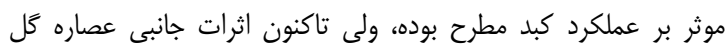

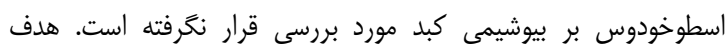

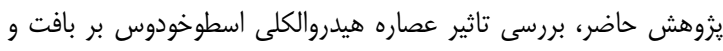

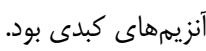

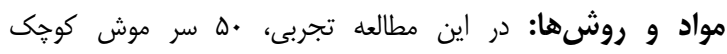

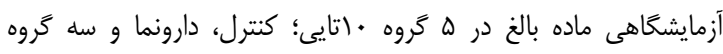

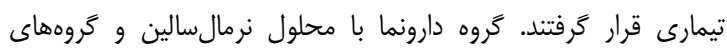

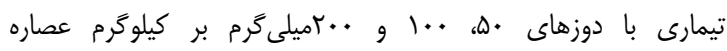

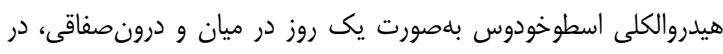

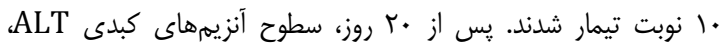

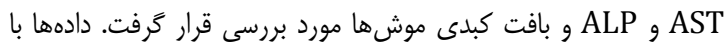

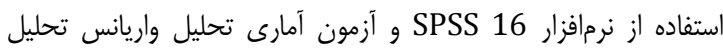

شدند.

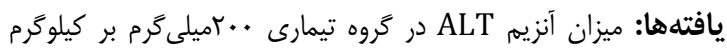

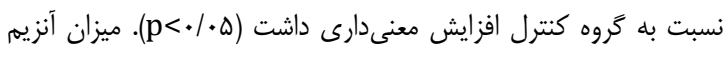
AST

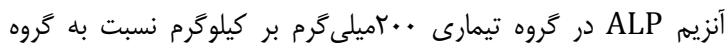

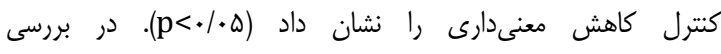

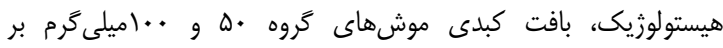

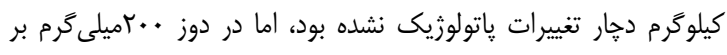

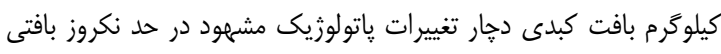

نتيجه كيرى: عصاره هيدروالكلى اسطوخودوس در دو دوز ..1 و

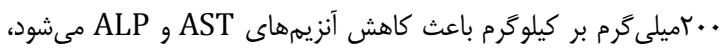

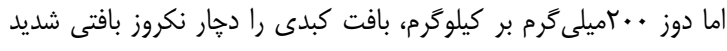

مىنمايد.

كليدوازهها: عصاره، كبد، موش

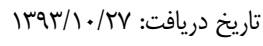

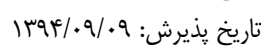

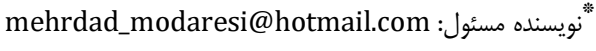




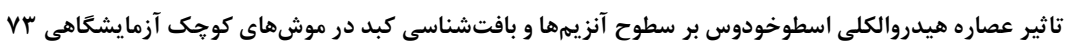

مورد بررسى قرار ترفت.

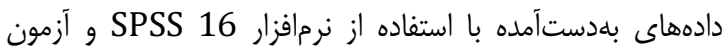
آمارى تحليل واريانس تجزيه و تحليل شدند.

يافتهها

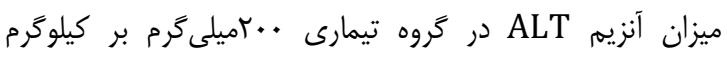

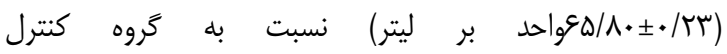

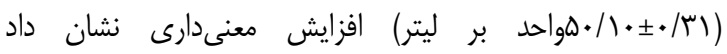

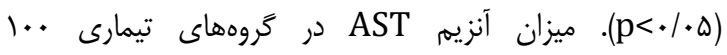
( )

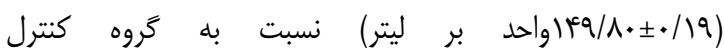

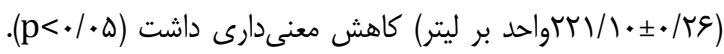

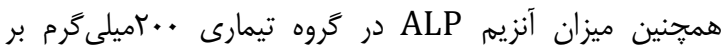

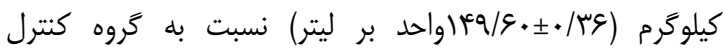

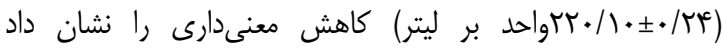

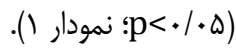

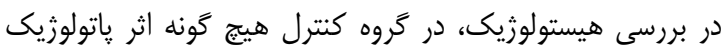

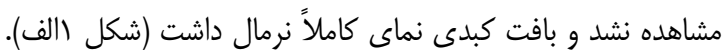

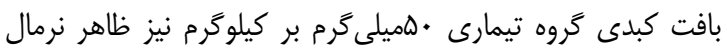

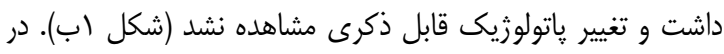

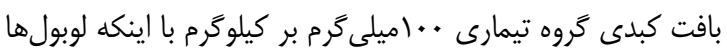

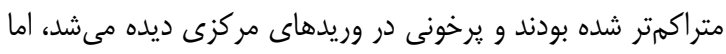

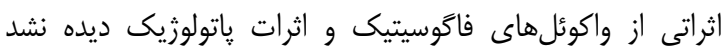

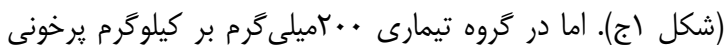

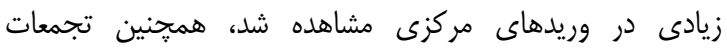

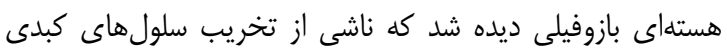

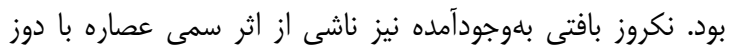

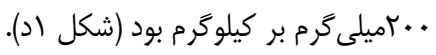

كل هاى تازه برداشتشده، بلطور كامل خشك شده و بهمنظور تهييه

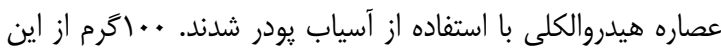

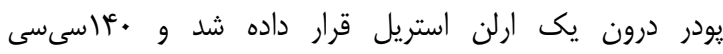

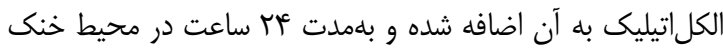

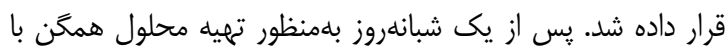

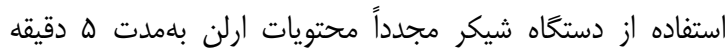

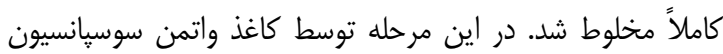

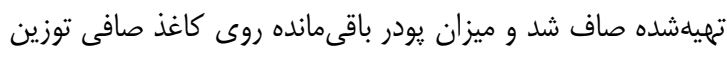

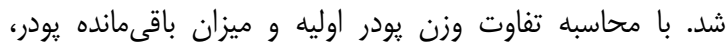

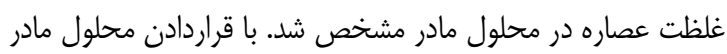

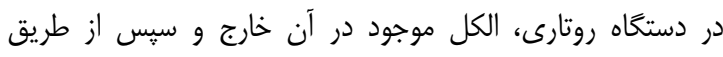

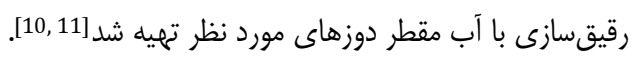

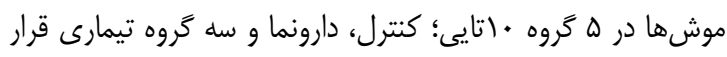

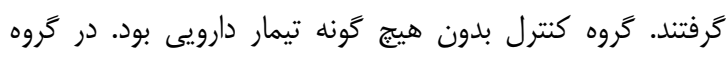

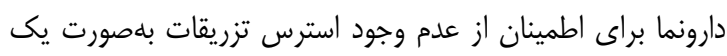

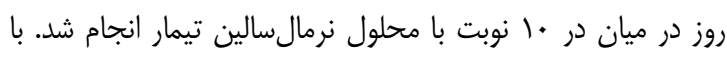

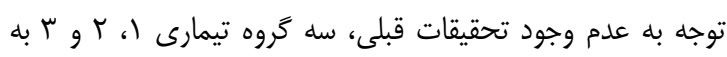

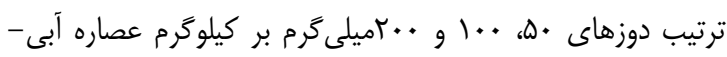

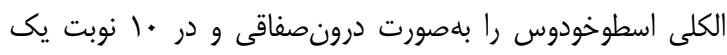

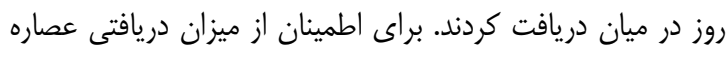

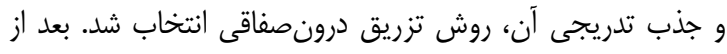

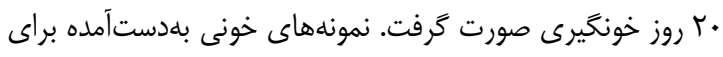
اندازهيرى آنزيمهاى كبدى ALT، AST و و

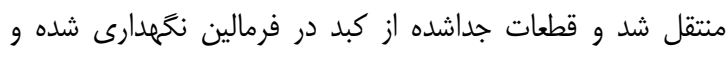
براى تهيه مقاطع بافتشناسى بلهروش هماتوكسيلين - ائوزين مورد

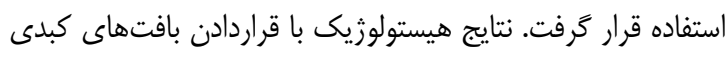

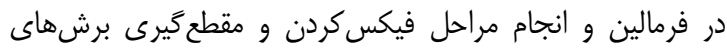

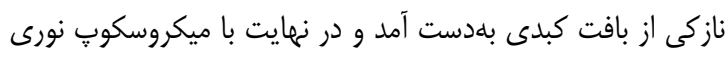

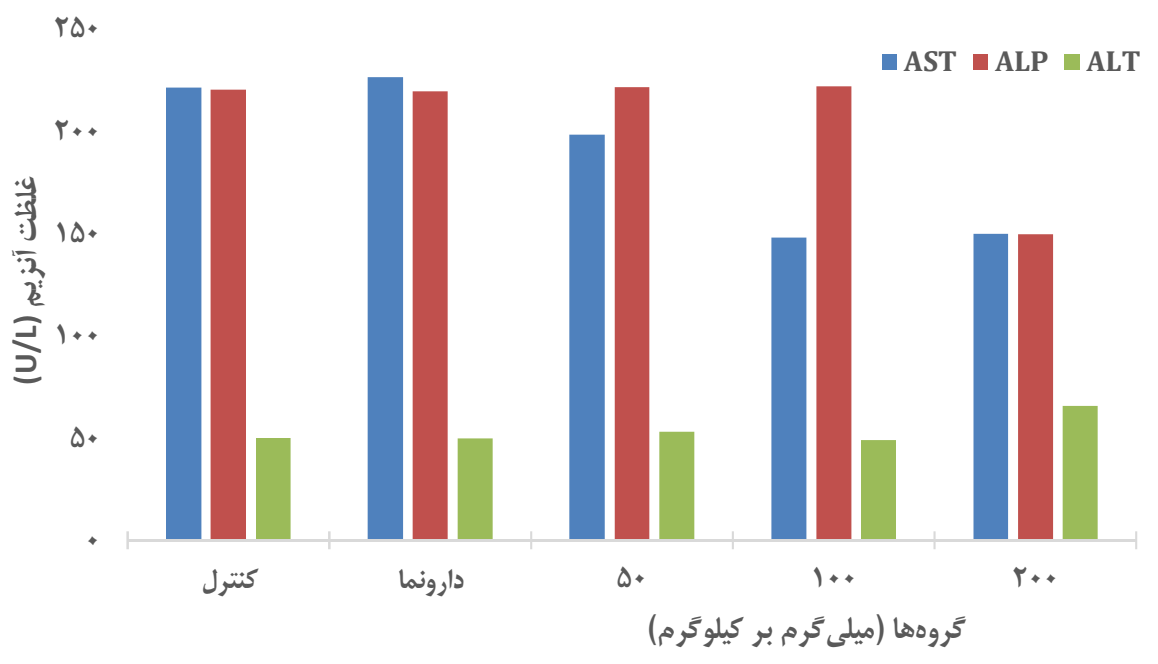

نمودار () مقايسه سطوح سرمى آنزيمهاى ALT AST ALP در كروه كنترل، دارونما و كروههاى تيمارى 

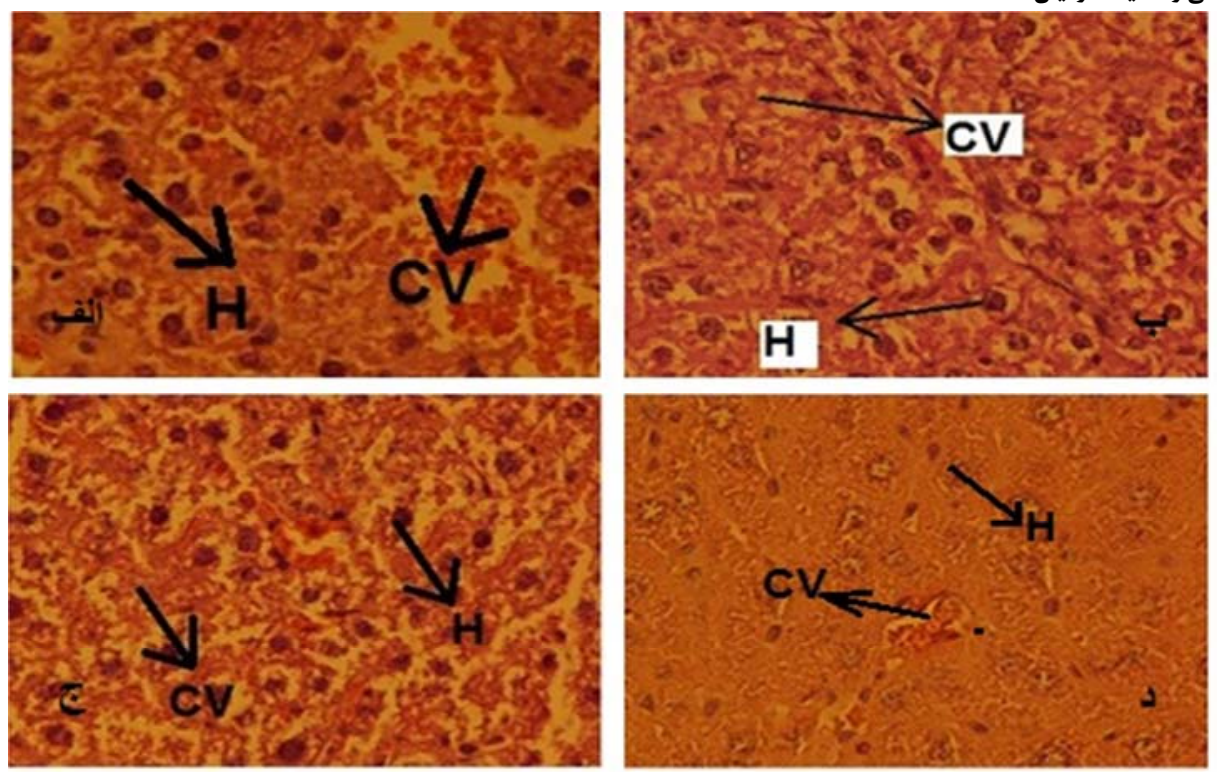

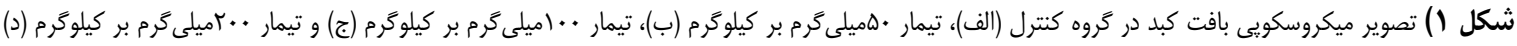

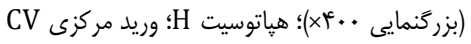

براساس مطالعات قبلى، لينالول و مشتقات آن موجب كاهش قابل

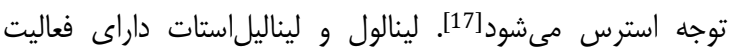

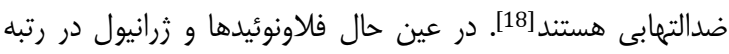

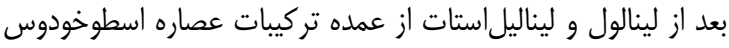

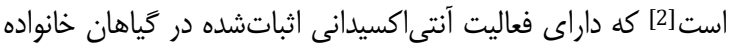

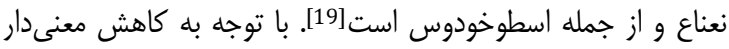

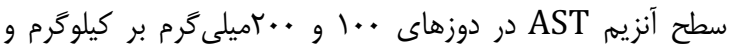

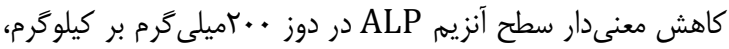

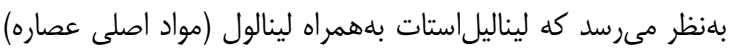
با نقش ويزه در كاهش استرس در اين طرح موثر بوده است [11]. اين

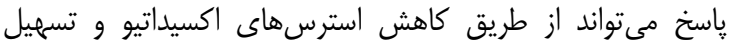

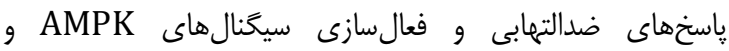
PPAR- $\alpha$

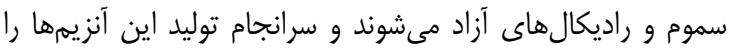

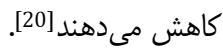

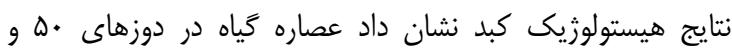

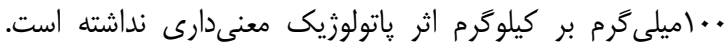

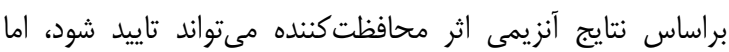

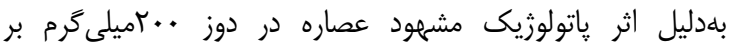
كيلوكرم بر بافت كبدى كه باعث نكروزهشدن آن و در نتيجه

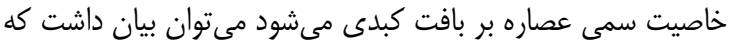

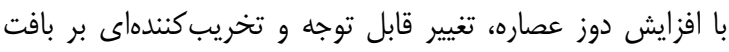

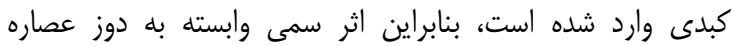

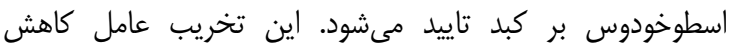

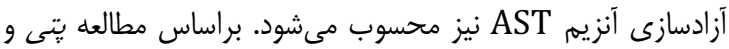

كياهان دارويى بهعلت فعاليت آنتىاكسيدانى و عوارض كهم، مورد

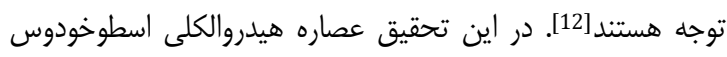

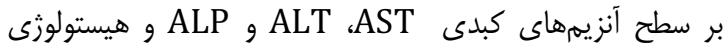

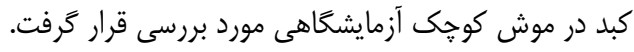

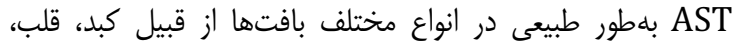

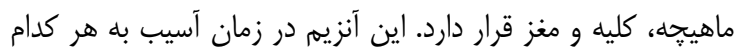

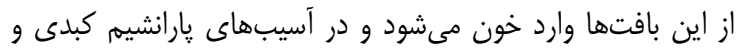

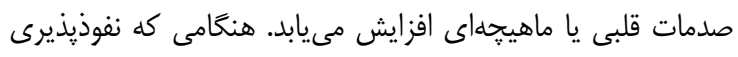

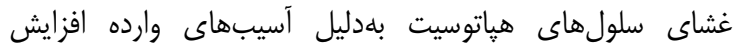

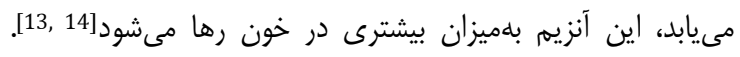

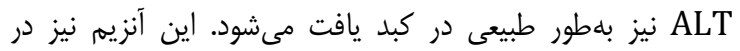

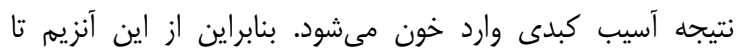

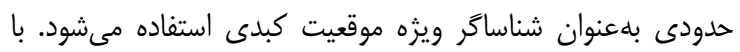
توجه به نتايج حاصل از اين تحقيق، اثر عصاره هيدروالكلى اين كَياه

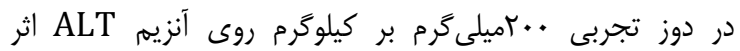
افزايشى داشته است، در حالى كه كاربرد عصاره بادرنجبويه با غارئ غلظت

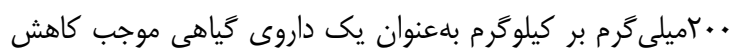

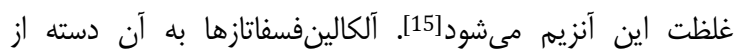

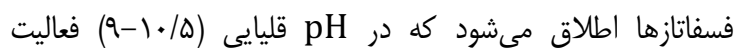

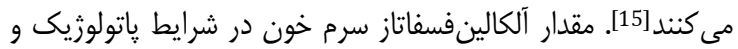
در ضايعات استخوانى و كبدى افزايش مىيابد. در افراد باد بالغ آنزيم آنيم

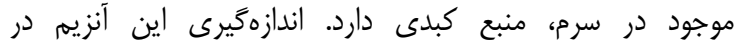

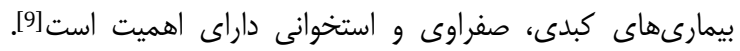

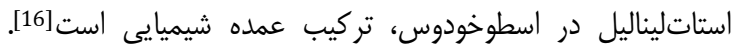


تاثير عصاره هيدروالكلى اسطوخودوس بر سطوح آنزيمها و بافتشناسى كبد در موشهاى كوجى آزمايشگاهى

3- Modaresi M, Pouriyanzadeh A. Effect of ocimum basilicum hydro alcoholic extract against pentylenetetrazole-induced seizure in mice. Armaghane-Danesh. 2013;18(8):615-21. [Persian]

4- Sarker SD, Nahar L. Natural medicine: the genus Angelica. Curr Med Chem. 2004;11(11)1479-500.

5- Rezania A, Sharifi G, Modaresi M. The effects of creatine and glutamine supplements along with resistance training on AST level in female mice. J Chem Pharm Res. 2015;7(11):361-5.

6- Balchin M. Lavender: The Genus Lavandula. Boca Raton, Florida: CRC Press; 2003.

7- Salamati A, Mashouf S, Sahbaei F, Mojab F. Effects of inhalation of lavender essential oil on open-heart surgery pain. Iran J Pharm Res. 2014;13(4):1257-61.

8- Chien LW, Cheng SL, Liu CF. The effect of lavender aromatherapy on autonomic nervous system in midlife women with insomnia. Evid Based Complement Alternat Med. 2012;2012:740-813.

9- Lee IS, Lee GJ. Effects of lavender aromatherapy on insomnia anddepression in women college students. Taehan Kanho HakhoeChi. 2006;36(1):136-43.

10- Modaresi M. Effect of Angelica archangelica root hydro-alcoholic extract on the blood cells of small laboratory mice. Horizon Med Sci. 2013;18(4):149-53. [Persian]

11- Modaresi M, Naderi B. Effect of Purslane (Portulaca oleracea) extracts on the electrophoretic pattern of blood proteins in mice. Horizon Med Sci. 2014;19(4):206-11. [Persian]

12- Osawa T, Kato Y. Protective role of antioxidative food factors in oxidative stress caused by hyperglycemia. Ann N Y Acad Sci. 2005;1043:440-51.

13- Field T, Field T, Cullen C, Largie S, Diego $M$, Schanberg $\mathrm{S}$, et al. Lavender bath oil reduces stress and crying and enhances sleep in very young infants. Early Hum Dev. 2008;84(6):39940.

14- Cohen-Naftaly M, Friedman SL. Current status of novel antifibrotic therapies in patients with chronic liver disease. Therap Adv Gastroenterol. 2011;4(6):391-417.

15- Maliakal PP, Wanwimolruk S. Effect of herbal teas on hepatic drug metabolizing enzymes in rats. J Pharm Pharmacol. 2001;53(10):1323-9.

16- Shiina Y, Funabashi N, Lee K, Toyoda T, Sekine T, Honjo S, et al. Relaxation effects of lavender aromatherapy improve coronary flow velocity reserve in healthy men evaluated by transthoracic Doppler echocardiography. Int J Cardiol. 2008;129(2):193-7.

17- Nakamura A, Fujiwara S, Matsumoto I, Abe K. Stress repression in restrained rats by (R)-(-)-linalool inhalation and gene expression profiling of their whole blood cells. J Monagric Food Chem. 2009;57(12):5480-5.

18- Peana AT, D'Aquila PS, Panin F, Serra G, Pippia P, Moretti MD. Anti-inflammatory activity of linalool and linalyl acetate constituents of essential oils. Phytomedicine. 2002;9(8):721-6.

19- Carnesecchi S, Bras-Gonçalves R, Bradaia A, Zeisel M, Gossé F, Poupon MF, et al. Geraniol, a component of plant essential oils, modulates DNA synthesis and potentiates 5 -fluorouracil efficacy on human colon tumor xenografts. Cancer Lett. 2004;215(1):53-9.

20- Fismer KL, Pilkington K. Lavender and sleep: A systematic reviewof the evidence. Eur J Integr Med. 2012;4(4):e436-47.

21- Petti C, Vegetti C, Molla A, Bersani I, Cleris L, Mustard $\mathrm{KJ}$, et al. AMPK activators inhibit the proliferation of human melanomas bearing the activated MAPK pathway. Melanoma Res. 2012;22(5):341-50.

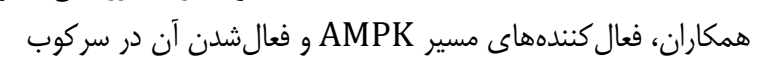

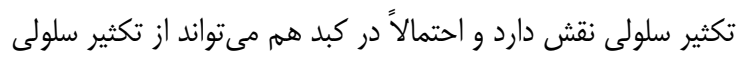

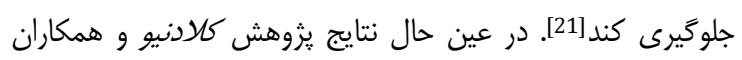

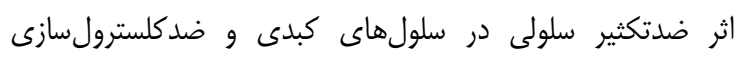

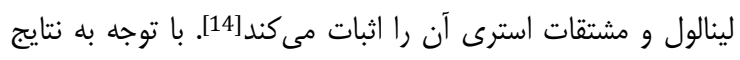

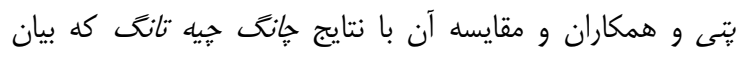

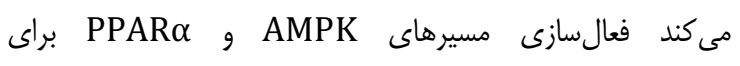

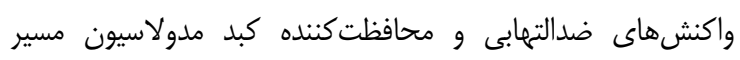

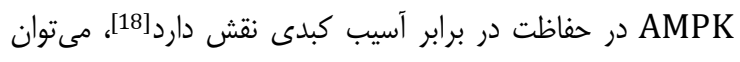

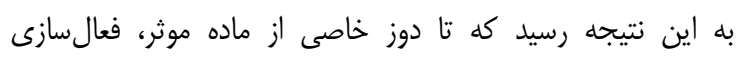

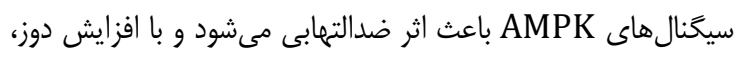

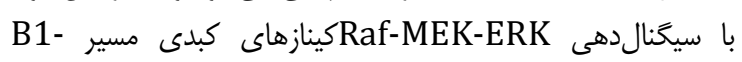

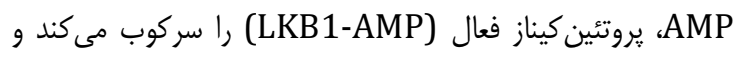

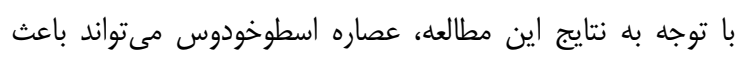

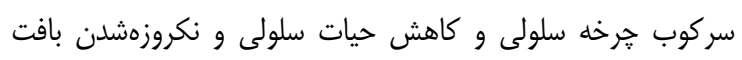

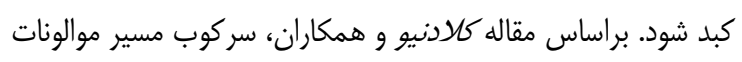

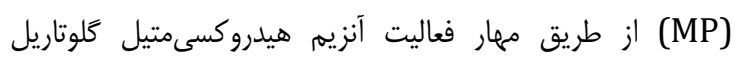

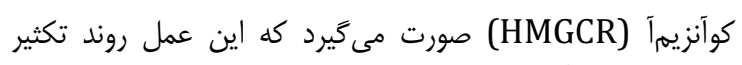

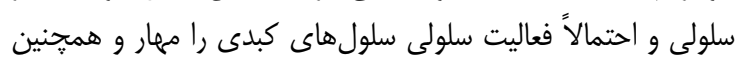

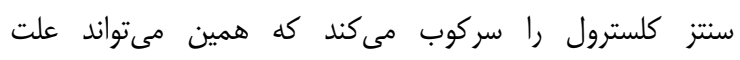
نكروزهشدن بافت كبد در بررسى هيستولوزيك باشد [21]. نتيجه كيرى

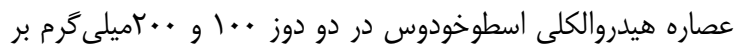

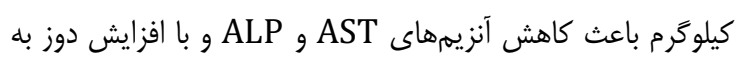

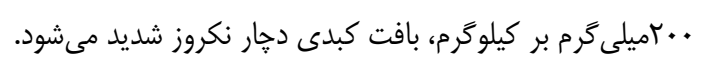

تشكر و قدردانى: از كليه همكاران بخش زيستشناسى دانشعاه

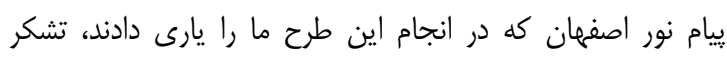
مى شود.

تاييديه اخلاقى: يروتكل اين تحقيق براساس قوانين بينالمللى

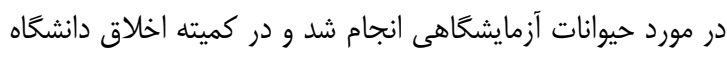

$$
\text { ييام نور اصفهان به تصويب رسيد. }
$$$$
\text { تعارض منافع: موردى توسط نويسندًان كزارش نشده است رست }
$$$$
\text { منابع مالى: توسط دانشخاه بيام نور اصفهان تامين شده است. }
$$

منابع

1- Barros L, Carvalho AM, Ferreira IC. Leaves, flowers, immature fruits and leafy flowered stems of Malva sylvestris: A comparative study of the nutraceutical potential and composition. Food Chem Toxicol. 2010;48(6):1466-72.

2- Modaresi M, Messripour M, Asadi Marghmaleki M, Hamadanian MK. Effect of saffron (Crocus sativus) extract on level of FSH, LH and testosterone in mice. J Zanjan Univ Med Sci. 2008;16(63):11-8. [Persian] 